
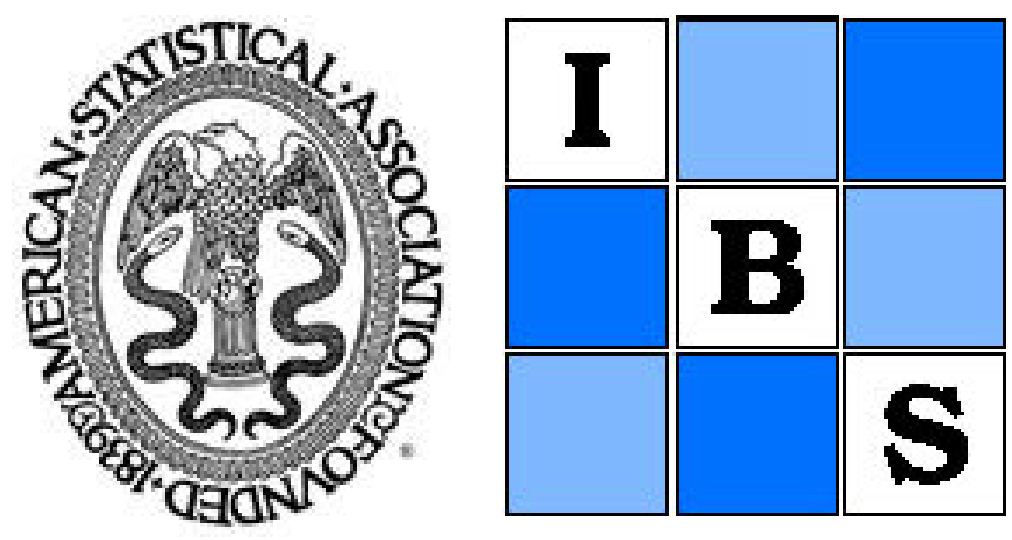

Titi (Sooty Shearwaters) on Whero Island: Analysis of Historic Data Using Modern Techniques Author(s): R. Paul Scofield, David J. Fletcher, Christopher J. R. Robertson Source: Journal of Agricultural, Biological, and Environmental Statistics, Vol. 6, No. 2, Estimation of Animal Abundance and Related Parameters (Jun., 2001), pp. 268-280 Published by: American Statistical Association and International Biometric Society Stable URL: http://www.jstor.org/stable/1400475

Accessed: $11 / 11 / 2008$ 14:25

Your use of the JSTOR archive indicates your acceptance of JSTOR's Terms and Conditions of Use, available at http://www.jstor.org/page/info/about/policies/terms.jsp. JSTOR's Terms and Conditions of Use provides, in part, that unless you have obtained prior permission, you may not download an entire issue of a journal or multiple copies of articles, and you may use content in the JSTOR archive only for your personal, non-commercial use.

Please contact the publisher regarding any further use of this work. Publisher contact information may be obtained at http://www.jstor.org/action/showPublisher?publisherCode=astata.

Each copy of any part of a JSTOR transmission must contain the same copyright notice that appears on the screen or printed page of such transmission.

JSTOR is a not-for-profit organization founded in 1995 to build trusted digital archives for scholarship. We work with the scholarly community to preserve their work and the materials they rely upon, and to build a common research platform that promotes the discovery and use of these resources. For more information about JSTOR, please contact support@ jstor.org.

American Statistical Association and International Biometric Society are collaborating with JSTOR to digitize, preserve and extend access to Journal of Agricultural, Biological, and Environmental Statistics. 


\title{
Titi (Sooty Shearwaters) on Whero Island: Analysis of Historic Data Using Modern Techniques
}

\author{
R. Paul SCOFIELD, David J. FleTCHER, and Christopher J. R. ROBERTSON
}

A reanalysis of titi (sooty shearwater, Puffinus griseus) banding data collected between 1940 and 1957 by Lance Richdale demonstrates that well-documented archival material can be usefully reanalyzed using newly developed statistical techniques. In this study, we compare the results obtained by Richdale using empirical techniques to those obtained using a multistate mark-recapture model. Although the two approaches produce similar estimates for some of the parameters, the multistate model additionally provides estimates of precision and can be used to answer biologically significant questions not raised by the original worker. Our analysis provides some evidence for two conclusions that Richdale put forward but could not justify rigorously: (a) nonbreeders have a lower survival rate than breeders, although the difference is not statistically significantly; and (b) nonbreeders are more difficult to capture than breeders. We argue that reanalysis should be carried out more frequently on historical data and lament the fact that it can be rare for such data to be made available for future scrutiny.

Key Words: Archival data; Mark-recapture, Multistate model; Puffinus griseus; Reanalysis.

\section{INTRODUCTION}

Reanalysis of historic data using modern statistical techniques is rarely attempted in wildlife biology due to the difficulties in interpreting the work of others and the perceived need for original results. Yet in order to establish whether changes have occurred in a species' demographic parameters, it is necessary to have an historical baseline. Any comparison between current and historical parameters will be more reliable if the two sets of estimates have been calculated using the same statistical methods with appropriately calculated margins of error. In wildlife biology, this is rarely done. Modern statistical techniques

R. Paul Scofield is with the Department of Zoology, University of Otago, Box 56, Dunedin, New Zealand (E-mail: paul. scofield@stonebow.otago.ac.nz). David J. Fletcher is with the Department of Mathematics and Statistics, University of Otago, Box 56, Dunedin, New Zealand. Christopher J. R. Robertson is with the Science and Research Division, Department of Conservation, Box 10-420, Wellington, New Zealand. 
to establish survival rates often involve assumptions that are different from those implicit in empirical estimation, making any comparison difficult.

Lance E. Richdale wrote one of the classic premodeling papers that attempts to estimate the survival rate of a pelagic seabird, the titi (sooty shearwater, Puffinus griseus; Richdale 1963). Richdale's estimates were based entirely on the return rate of individuals and did not incorporate the probability of recapture. Thus, he had to allow for missing individuals by subtle and involved data adjustment. This made it nigh impossible for him to calculate the error associated with his estimates of survival.

\subsection{Aims}

Our reanalysis of Richdale's data was carried out as part of a multidisciplinary study to assess whether traditional harvest is having an impact on the viability of the titi population (Teiepa et al. 1997). Our aims in reexamining Richdale's 1963 paper were to

(1) obtain statistically rigorous estimates of survival as input to population models that can be used to assess the consequences of harvest and

(2) determine whether reanalysis of historic data gives an opportunity to estimate parameters that were not considered by the original researcher.

\section{METHODS}

\subsection{DATA}

Between 1940 and 1957, Lancelot E. Richdale studied a small colony of titi on Whero Island, a granite outcrop of about 0.2 hectares off the northeast coast of Stewart Island (Rakiura) in southern New Zealand $\left(46^{\circ} 55^{\prime} \mathrm{S}, 168^{\circ} 12^{\prime} \mathrm{E}\right)$. Richdale initially focused on the smaller petrels; it was not until 1942 that he began banding titi. Richdale visited Whero Island in 1942, 1943, 1944, 1949, 1952, 1953, and 1956 to recapture titi, giving seven capture occasions over a 15-year period (no captures were made during the other 8 years). His work resulted in a number of general works, 12 papers on other species, and 4 papers on the biology of titi, including

(1) "The Sooty Shearwater in New Zealand" (Richdale 1944),

(2) "The Nestling of the Sooty Shearwater" (Richdale 1945),

(3) "Duration of Parental Attentiveness in the Sooty Shearwater" (Richdale 1954), and

(4) "The Biology of the Sooty Shearwater Puffinus griseus" (Richdale 1963).

The foraging rates recorded by Richdale $(1945,1954,1963)$ have been reanalyzed several times to exemplify the low feeding frequency and cyclic colony attendance of parent petrels (e.g., Lack 1968; Ricklefs, Day, Huntington, and Williams 1985; Oka, Maruyama, and Skira 1987; Hamer and Hill 1993; Weimerskirch 1998). No one has reanalyzed his demographic data. Unless stated, "Richdale" below refers to Richdale (1963). 
Lance Richdale was a meticulous worker; the field notes and calculations for his published results are deposited in the Hocken Library of the University of Otago (Hocken Library MS 1260/81/12). The basis of this paper is a retabulation of the capture history of each of 903 individually banded birds, taken directly from Richdale's field notes. Once collated, the full set of recapture histories was analyzed using the mark-recapture program MARK (White and Burham 1999).

\subsection{Models}

\subsubsection{Multistate Model}

Richdale placed each bird in one of the following four categories, depending on where it was captured:

(1) breeder,

(2) keeping company with another bird in a burrow,

(3) alone in a burrow, or

(4) on the surface.

This meant we could consider using a multistate model, with the states corresponding to these four categories. Our motivation for using this type of model is that it allows us to address important biological questions by providing estimates of survival rate and capture rate separately for each state as well as the probability of a transition from one state to another (Arnason 1972, 1973; Brownie, Hines, Nichols, Pollock, and Hestbeck 1993; Schwart, Schweigert, and Arnason 1993; Nichols and Kendall 1995; Cam, Hines, Monnat, Nichols, and Danchin 1998). In this article, we focus on models that allow us to estimate the following:

(1) mean and year-to-year variation in annual survival rate,

(2) differences between breeders and nonbreeders in both mean and year-to-year variation in survival, and

(3) mean and year-to-year variation in the rates of transition both from breeder to nonbreeder and vice versa.

We encountered convergence problems using the original four states with these models due to the sparseness of the data. In order to overcome this, we reduced the number of states by assuming that all birds in categories $2-4$ were nonbreeders, giving just two states, i.e., breeders (B) and nonbreeders (NB). The nonbreeders included both birds that had bred previously (birds that skip a breeding seasons and divorcees) and birds that had yet to breed (prebreeders). Because Richdale did not check burrows before hatching, it is likely that some of the birds in categories $2-4$ had already failed that season, suggesting that our assumption may not be reasonable (approximately $92 \%$ of breeding failures for this species appear to occur before the second week in January; Hunter and Scofield, unpublished data). We therefore regard those birds in the breeding category as successful breeders and those in the other category as nonbreeders plus prebreeders and failed breeders. The multivariate 
Table 1. Multivariate m-Array Summary of the Data

\begin{tabular}{|c|c|c|c|c|c|c|c|c|c|c|c|c|c|c|c|}
\hline \multirow[b]{3}{*}{ Period } & \multirow[b]{3}{*}{ State } & \multirow{3}{*}{$\begin{array}{l}\text { Number } \\
\text { captured }\end{array}$} & \multirow{3}{*}{$\begin{array}{l}\text { Period: } \\
\text { State: }\end{array}$} & \multicolumn{12}{|c|}{ Number first recaptured } \\
\hline & & & & \multicolumn{2}{|c|}{$\begin{array}{l}1943- \\
1944\end{array}$} & \multicolumn{2}{|c|}{$\begin{array}{l}1944- \\
1945\end{array}$} & \multicolumn{2}{|c|}{$\begin{array}{l}1949- \\
1950\end{array}$} & \multicolumn{2}{|c|}{$\begin{array}{l}1952- \\
1953\end{array}$} & \multicolumn{2}{|c|}{$\begin{array}{l}1953- \\
1954\end{array}$} & \multicolumn{2}{|c|}{$\begin{array}{l}1956- \\
1957\end{array}$} \\
\hline & & & & $B$ & NB & $B$ & $N B$ & $B$ & NB & $B$ & $N B$ & $B$ & $N B$ & $B$ & $N B$ \\
\hline \multirow[t]{2}{*}{$1942-1943$} & B & 29 & & 8 & 2 & 6 & 0 & 3 & 0 & 1 & 0 & 0 & 0 & 0 & 0 \\
\hline & NB & 114 & & 19 & 17 & 6 & 7 & 6 & 4 & 3 & 0 & 1 & 0 & 0 & 0 \\
\hline \multirow[t]{2}{*}{$1943-1944$} & B & 104 & & & & 47 & 1 & 13 & 0 & 5 & 0 & 8 & 0 & 0 & 1 \\
\hline & NB & 89 & & & & 12 & 18 & 9 & 4 & 5 & 1 & 1 & 2 & 1 & 0 \\
\hline \multirow[t]{2}{*}{$1944-1945$} & B & 99 & & & & & & 35 & 0 & 10 & 0 & 15 & 0 & 1 & 0 \\
\hline & NB & 88 & & & & & & 15 & 14 & 5 & 6 & 3 & 11 & 1 & 0 \\
\hline \multirow[t]{2}{*}{$1949-1950$} & $\mathrm{~B}$ & 169 & & & & & & & & 47 & 1 & 55 & 1 & 1 & 3 \\
\hline & NB & 147 & & & & & & & & 12 & 15 & 12 & 47 & 2 & 7 \\
\hline \multirow[t]{2}{*}{ 1952-1953 } & $\mathrm{B}$ & 121 & & & & & & & & & & 87 & 2 & 1 & 1 \\
\hline & NB & 94 & & & & & & & & & & 25 & 45 & 3 & 4 \\
\hline \multirow[t]{2}{*}{$1953-1954$} & $\mathrm{~B}$ & 180 & & & & & & & & & & & & 5 & 17 \\
\hline & NB & 344 & & & & & & & & & & & & 3 & 136 \\
\hline
\end{tabular}

$m$-array (Brownie et al., 1993) for the analysis is given in Table 1. We performed all analyses using the multistate option within MARK (White and Burham 1999) and used the random effects option to obtain estimates of mean and year-to-year variation for each parameter (Burnham, in press).

\subsubsection{Model Notation}

The parameters used in the multistate models are

$p_{t}^{r}=$ probability that a bird is recaptured at time $t$ in state $r$, given that it is alive and in the study area,

$S_{t}^{r}=$ probability that a bird that is in state $r$ at time $t$ survives until time $t+1$,

$\psi_{t}^{r s}=$ probability that a bird that is in state $r$ at time $t$ is in state $s$ at time $t+1$, given that it survived from time $t$ to time $t+1$.

The transition parameters can be interpreted as follows. $\psi_{t}^{\mathrm{B}, \mathrm{NB}}$ is the probability that a bird that was breeding in year $t$ was not breeding in the following year (given that it was still alive). The value of this parameter will be influenced by

- birds skipping a season, i.e., taking a "sabbatical,"

- possible reproductive depression due to senescence,

- birds who divorce and are unable to find a new mate, and

- breeding burrow loss, which was substantial on Whero Island in the late 1950s (Richdale 1963).

$\psi_{t}^{\mathrm{NB}, \mathrm{B}}$ is the probability that a bird that was not breeding in year $t$ was breeding in the following year (given that it was still alive), and its value will be influenced by

- recruitment into the breeding population from the prebreeders,

- birds resuming breeding after taking a sabbatical, and 
Table 2. Model Notation Used in the Analyses

\begin{tabular}{ll}
\hline \multicolumn{1}{c}{ Notation } & \multicolumn{1}{c}{ Meaning } \\
\hline$S_{t}^{r}, p_{t}^{r}, \psi_{t}^{r s}$ & Parameters vary with both time and breeding state \\
$S^{r}, p^{r}, \psi^{r s}$ & Parameters vary with breeding state but constant over time \\
$S, p, \psi$ & Parameters constant over both time and breeding state \\
$S_{b+t}, p_{b+t}, \psi_{b+t}$ & Parameters vary with time in same way for all breeding states \\
\hline
\end{tabular}

- divorcees finding new mates.

The notation we used to distinguish the different models is summarized in Table 2.

\subsubsection{Analysis}

The first step in the analysis was to assess the goodness of fit of the most general model, in which all parameters were allowed to vary according to the year and state of the bird (the Arnason-Schwarz model, denoted $S_{t}^{r}, p_{t}^{r}, \psi_{t}^{r s}$ in Table 2). We assessed goodness of fit using the program MSSURVIV (Brownie et al. 1993). We subsequently compared alternative models using a modified version (QAICc) of Akaike's Information Criterion (White and Burham 1999).

\subsubsection{Relating Capture Rate to Effort}

In estimating survival rate, it can be of benefit to allow for any relationship between capture rate and field effort (Lebreton, Burnham, Clobert, and Anderson 1992). Richdale's field effort varied because he was working on the biology of a number of different species while on Whero Island and the amount of effort he afforded each species varied between years. He generally worked alone or had companions give him a little help with his field work (Richdale 1942,1943). We decided to use the number of days his notes mentioned capture of titi as a measure of effort. Table 3 summarizes our calculations (from his notebook) and compares them with those in Richdale (1963).

Table 3. Estimates of Effort From Richdale (1963) and From His Notebooks. From both sources, it is clear that he spent January $6-18,1954$, off the island; this period away is allowed for in the figures shown.

\begin{tabular}{|c|c|c|c|c|c|c|}
\hline \multirow[b]{2}{*}{ Season } & \multicolumn{3}{|c|}{ Richdale (1963) } & \multicolumn{3}{|c|}{ Notebooks } \\
\hline & Arrival & Departure & Nights & Started & Finished & Nights \\
\hline $1942-1943$ & December 1 & January 31 & 61 & December 20 & January 21 & 32 \\
\hline $1943-1944$ & December 20 & February 12 & 54 & January 7 & February 10 & 27 \\
\hline 1944-1945 & December 19 & February 15 & 58 & January 25 & February 7 & 20 \\
\hline $1949-1950$ & January 16 & March 8 & 51 & January 16 & March 6 & 49 \\
\hline $1952-1953$ & February 4 & May 12 & 97 & February 5 & May 8 & 92 \\
\hline \multirow[t]{2}{*}{ 1953-1954 } & December 9 & February 20 & 61 & December 9 & January 6 & \\
\hline & & & & January 18 & February 18 & 59 \\
\hline $1956-1957$ & December 21 & February 17 & 58 & December 23 & February 15 & 54 \\
\hline
\end{tabular}


In order to assess whether it would be worth considering models in which capture rate was specified as a linear function (on a logistic scale) of our measure of effort, we used the random effects option within MARK to estimate the strength of this relationship (see White and Burnham (1999) for details) for the model with the lowest QAICc. We could have specified such a relationship within the main design matrix option of MARK and used QAICc to compare this model with others in the usual way. The advantage of the random effects approach is that it allows for error in that we do not need to assume that the true capture rates are perfectly related to field effort.

\subsubsection{Unequal Sampling Intervals}

Currently, the multistate option in MARK does not cope with unequal time intervals between capture occasions. To cope with this, we entered the data as if there were field effort in each of the 15 years of the study, inserting zeros in the capture histories for those years during which Richdale was not on the island. For each model, we specified the capture probability in each of those years to be zero. In addition, we set both the survival and transition probabilities to be constant over a period during which there was no effort.

\subsubsection{Assumptions and Limitations}

There are a number of assumptions and limitations inherent in our analysis:

(1) As in any mark-recapture analysis, the survival rate is really the "apparent" survival rate; it tells us the probability that a bird survives and stays in the study area.

(2) The multistate models we have used are Markovian, meaning we assume that the probability of a bird being in a particular state depends only on its state in the previous year. At present, a non-Markovian analysis is not possible within the program MARK.

(3) We cannot assess any differences between males and female because Richdale did not sex his study birds.

\subsection{Abundance}

We estimated abundance using the approach described in Loery, Nichols, and Hines (1997). This involved calculating

$$
\hat{N}_{i}^{r}=n_{i} / \hat{p}_{i}^{r} \quad \text { and } \quad \mathrm{CV}\left(\hat{N}_{i}^{r}\right)=\mathrm{CV}\left(\hat{p}_{i}^{r}\right)
$$

where $\hat{N}_{i}^{r}$ is the estimate of the number of birds in state $r$ in year $i, n_{i}$ is the total number of birds caught in year $i, \hat{p}_{i}^{r}$ is the estimate of the capture probability for birds in state $r$ in year $i$, and $\mathrm{CV}=\mathrm{SE} /$ estimate.

\subsection{Differences in Capture Rates}

Richdale (p. 83) discussed the higher 'apparent mortality' he found in the nonbreeding birds (see Discussion section for details). He argued that nonbreeders were mostly young 
and therefore

(1) were difficult to catch compared with capturing breeders in their burrows,

(2) included transients,

(3) included birds that had immigrated or would emigrate,

(4) contained a large proportion that could be caught only at night, unlike breeders,

(5) arrived on the breeding ground later than the breeders and left earlier, and

(6) came ashore at infrequent intervals and never on moonlit nights.

He believed that this higher apparent mortality was due to a lower capture rate for nonbreeders and attempted to test for this using empirical methods.

\subsection{Potential Effect of Transients on Survival Estimation}

Our estimate of survival is "apparent" in the sense that it will be affected by emigration. In particular, transient birds that are present for just one season may cause the estimate for the resident population to be misleadingly low. The goodness-of-fit test we carried out in MSSURVIVE is designed to detect such transience.

\section{RESULTS}

There was no significant overall lack of fit for the most general model, $S_{t}^{r}, p_{t}^{r}, \psi_{t}^{r s}$, suggesting that comparison of reduced versions of this model would be valid. In addition, this result suggests that our survival estimates should not suffer any significant bias that could be caused by transients, i.e., birds attending the colony for just 1 or 2 years.

We compared eight models, as shown in Table 4. We did not consider models in which either the survival or capture rate is assumed to be constant throughout the period of the study because this is biologically unrealistic. The random effects approach within MARK allowed us to estimate both the mean and year-to-year variation in survival and capture rate in a way that is more meaningful (Burnham, in press). We did consider models in which the transition rates were assumed to be constant, simply as a means of substantially reducing the number of parameters to be estimated.

Table 4. Comparison of Models

\begin{tabular}{crccc}
\hline \hline \multicolumn{1}{c}{ Model } & $\Delta$ AICc & AlCc Weight & Parameters & Deviance \\
\hline$S_{t}, p_{t}^{r}, \psi_{t}^{r s}$ & 0.00 & 0.9710 & 29 & $4,061.46$ \\
$S_{t}, p_{t}, \psi_{t}^{r s}$ & 7.10 & 0.0278 & 23 & $4,080.98$ \\
$S_{t}^{r}, p_{t}^{r}, \psi_{t}^{r s}$ & 13.52 & 0.0011 & 34 & $4,064.56$ \\
$S_{t}^{r}, p_{t}, \psi_{t}^{r s}$ & 76.57 & 0.0000 & 29 & $4,138.03$ \\
$S_{t}, p_{t}^{r}, \psi^{r s}$ & 164.41 & 0.0000 & 20 & $4,244.46$ \\
$S_{t}^{r}, p_{t}^{r}, \psi^{r s}$ & 170.74 & 0.0000 & 26 & $4,238.42$ \\
$S_{t}^{r}, p_{t}, \psi^{r s}$ & 338.46 & 0.0000 & 19 & $4,420.56$ \\
$S_{t}, p_{t}, \psi^{r s}$ & 342.58 & 0.0000 & 13 & $4,436.94$ \\
\hline
\end{tabular}


Table 5. Estimates of Annual Survival, With 95\% Confidence Limits, From the Best Two-State Model, $S_{t}, p_{t}^{r}, \psi_{t}^{r s}$. The mean and year-to-year standard deviation (SD) are also shown. Richdale's empirical estimates are also shown for comparison.

\begin{tabular}{|c|c|c|c|c|c|c|c|}
\hline & \multicolumn{5}{|c|}{ Period } & \multirow[b]{2}{*}{ Mean } & \multirow[b]{2}{*}{$S D$} \\
\hline & 1942-1943 & 1943-1944 & 1944-1949 & 1949-1952 & 1952-1953 & & \\
\hline Richdale & & & $93.4 \%$ & $89.3 \%$ & $90.3 \%$ & $90.9 \%$ & \\
\hline Estimate & $75.1 \%$ & $86.3 \%$ & $93.9 \%$ & $90.0 \%$ & $87.5 \%$ & $87.2 \%$ & $7.1 \%$ \\
\hline Lower limit & $65.7 \%$ & $77.4 \%$ & $91.5 \%$ & $87.3 \%$ & $82.1 \%$ & $80.2 \%$ & $2.5 \%$ \\
\hline Upper limit & $84.5 \%$ & $95.2 \%$ & $96.3 \%$ & $92.7 \%$ & $92.9 \%$ & $94.2 \%$ & $24 \%$ \\
\hline
\end{tabular}

The best model is clearly $S_{t}, p_{t}^{r}, \psi_{t}^{r s}$, in which the survival rates are assumed to be the same for breeders and nonbreeders. For this model, there was no evidence of a relationship between the capture rate and effort both for breeders and for nonbreeders. As the AICc Weight for this model is so high (0.97), we present the estimates from this model rather than those obtained by model averaging (Buckland, Burnham, and Augustin 1997). Table 5 gives the estimates of survival for each of the six periods of the study, together with Richdale's empirical estimates for three of these periods (he considered the data for the other periods to be too sparse for calculation of an estimate). Note that Richdale's method of estimation meant that he could not calculate confidence limits. The mean and betweenyear variation in survival for breeders and nonbreeders is shown in Table 6, while Table 7 gives the estimated transition rates.

\subsection{Abundance and Breeding Density}

Abundance estimates for both breeders and nonbreeders are shown in Table 8 and Figure 1. In 1953-1954, Richdale (p. 94) found 292 burrows in an area of $420 \mathrm{~m}^{2}$ (about 502 square yards) or 70 burrows $/ 100 \mathrm{~m}^{2}$. He thought that the density on Whero was similar to that elsewhere; however, Warham and Wilson (1982) found that on The Snares the mean density in the Poa tussock and Olearia forest (similar to the habitat on Whero) were 116 and 195 burrows $/ 100 \mathrm{~m}^{2}$, respectively. Richdale found that about $27-33 \%$ of burrows were never used and, in any given year, less than 100 burrows contained breeders. In 1949, 1952, and 1953 , this equates to apparent burrow occupancy of only 41,41 , and $28 \%$ by breeders. Richdale further estimated in 1953-1954 an overall density of 1.3 birds (of all categories)

Table 6. Estimates of the Mean and Year-to-Year Standard Deviation (SD) in Annual Survival, With 95\% Confidence Limits, for Breeders and Nonbreeders, From the Model $S_{t}^{r}, p_{t}^{r}, \psi_{t}^{r s}$

\begin{tabular}{lcrllr}
\hline \hline & \multicolumn{2}{c}{ Breeders } & & \multicolumn{2}{c}{ Nonbreeders } \\
\cline { 2 - 3 } & Mean & $S D$ & & Mean & \multicolumn{1}{c}{$S D$} \\
\hline Estimate & $91.9 \%$ & $2.0 \%$ & & $85.3 \%$ & $8.6 \%$ \\
Lower limit & $89.2 \%$ & $0.0 \%$ & & $76.9 \%$ & $3.4 \%$ \\
Upper limit & $94.6 \%$ & $11.7 \%$ & & $93.7 \%$ & $28.2 \%$ \\
\hline
\end{tabular}


Table 7. Estimates of Annual Transition Rates, With $95 \%$ Confidence Limits, From the Best Two-State Model, $S_{t}, p_{t}^{r}, \psi_{t}^{r s}$. The means and year-to-year standard deviations (SD) are also shown.

\begin{tabular}{|c|c|c|c|c|c|c|c|c|}
\hline & \multicolumn{6}{|c|}{ Period } & \multirow[b]{2}{*}{ Mean } & \multirow[b]{2}{*}{$S D$} \\
\hline & 1942-1943 & $1943-1944$ & 1944-1949 & 1949-1952 & 1952-1953 & 1953-1956 & & \\
\hline \multicolumn{9}{|c|}{ Breeder to Nonbreeder } \\
\hline Estimate & $14.4 \%$ & $2.0 \%$ & $0.0 \%$ & $0.5 \%$ & $1.7 \%$ & $35.5 \%$ & $7.6 \%$ & $14.1 \%$ \\
\hline Lower limit & $0.0 \%$ & $0.0 \%$ & $0.0 \%$ & $0.0 \%$ & $0.0 \%$ & $16.0 \%$ & $0.0 \%$ & $3.5 \%$ \\
\hline Upper limit & $32.4 \%$ & $5.8 \%$ & $0.0 \%$ & $1.4 \%$ & $3.9 \%$ & $55.0 \%$ & $20.0 \%$ & $42.2 \%$ \\
\hline \multicolumn{9}{|c|}{ Nonbreeder to Breeder } \\
\hline Estimate & $36.3 \%$ & $28.3 \%$ & $10.7 \%$ & $6.2 \%$ & $24.7 \%$ & $9.0 \%$ & $18.5 \%$ & $12.3 \%$ \\
\hline Lower limit & $22.0 \%$ & $14.6 \%$ & $6.2 \%$ & $2.8 \%$ & $16.6 \%$ & $0.7 \%$ & $7.7 \%$ & $6.2 \%$ \\
\hline Upper limit & $50.6 \%$ & $42.1 \%$ & $15.1 \%$ & $9.5 \%$ & $32.9 \%$ & $17.2 \%$ & $29.3 \%$ & $33.2 \%$ \\
\hline
\end{tabular}

per $\mathrm{m}^{2}$, or 551 birds in total. Table 8 summarizes Richdale's abundance and burrow density estimates for comparison with our results.

\subsection{Capture Rates}

The mean and year-to-year variation in the capture rates for breeders and nonbreeders are shown in Table 9. These results suggest that nonbreeders are harder to capture than breeders, as Richdale hypothesized. The year-to-year variation in capture rate is also greater for nonbreeders than for breeders.

\subsection{Transition Rates}

During 1942-1953, the rate at which birds that bred one year did not breed in the following year was consistently lower than the rate at which nonbreeders were becoming breeders. This pattern was dramatically reversed in the period 1953-1956 (see later discussion).

\section{DISCUSSION}

\subsection{Survival}

Using empirical methods, Richdale estimated the overall annual survival rate between 1944 and 1956 to be $90.9 \%$ (Table 5). Using a multistate mark-recapture model, we obtained

Table 8. The Number of Breeding Birds Caught (From Richdale's Unpublished Raw Data) and Our Estimates of Abundance (From Our Model-Based Analysis)

\begin{tabular}{cccccccc}
\hline \hline & $\begin{array}{c}\text { Richdale's count, } \\
\text { successful } \\
\text { year }\end{array}$ & \multicolumn{6}{c}{ Model based estimates } \\
\cline { 3 - 8 } & breeding birds & Breeders & SE & Nonbreeders & SE & Total & SE \\
\hline $1943-1944$ & $?$ & 196 & 35 & 241 & 56 & 437 & 66 \\
$1944-1945$ & $?$ & 194 & 21 & 247 & 50 & 441 & 55 \\
$1949-1950$ & 178 & 345 & 32 & 378 & 74 & 723 & 81 \\
$1952-1953$ & 194 & 279 & 25 & 465 & 90 & 745 & 94 \\
$1953-1954$ & 166 & 289 & 11 & 326 & 20 & 615 & 23 \\
\hline
\end{tabular}


Breeders

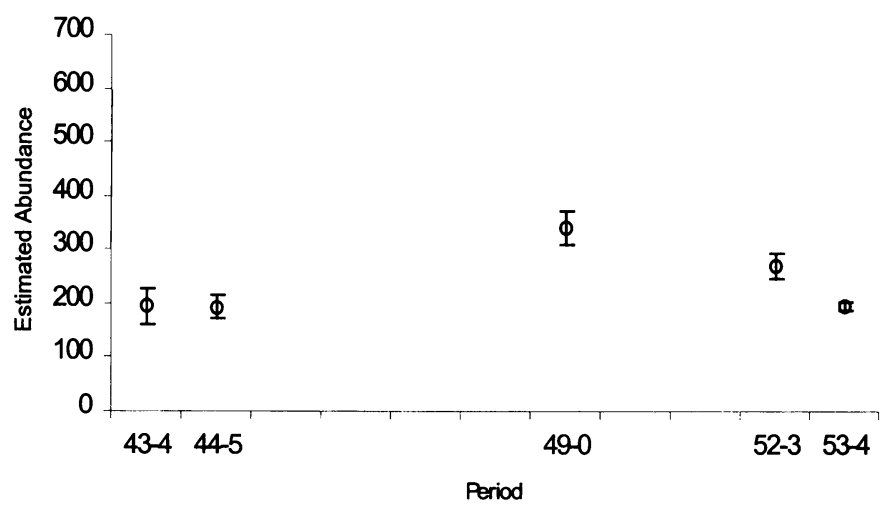

Non-Breeders

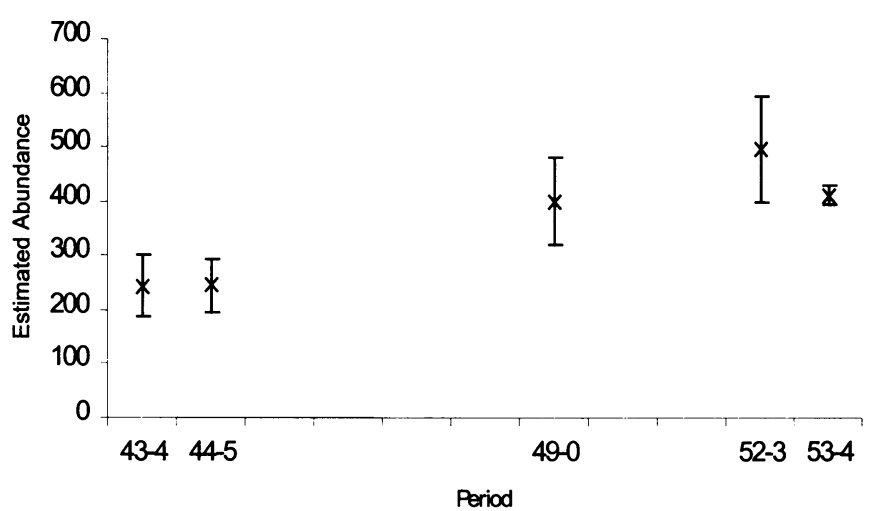

Figure 1. Estimated Abundance ( $\pm S E$ ) of Breeders and Nonbreeders on Whero Island During the Study Period. Each period corresponds to one austral summer. Abundance is number of birds estimated using the methodology of Loery et al. (1997).

a mean of $87.2 \%(\mathrm{SE}=3.5 \%)$ and a standard deviation of $7.1 \%$ during the period $1942-$ 1953. Part of the difference in these means appears to be due to Richdale's decision not to attempt estimation of survival for the earlier part of his study. These estimates compare with 93.1\% survival for Hutton's shearwater Puffinus huttoni (Cuthbert, Fletcher, and Davis, in

Table 9. Estimates of the Mean and Year-to-Year Standard Deviation (SD) in Capture Rate, With 95\% Confidence Limits, for Breeders and Nonbreeders, From the Model $S_{t}, p_{t}^{r}, \psi_{t}^{r s}$

\begin{tabular}{lcrllr}
\hline & \multicolumn{2}{c}{ Breeders } & & \multicolumn{2}{c}{ Nonbreeders } \\
\cline { 2 - 3 } \cline { 5 - 6 } & Mean & $S D$ & & Mean & $S D$ \\
\hline Estimate & $57 \%$ & $16 \%$ & & $43 \%$ & $23 \%$ \\
Lower limit & $41 \%$ & $9 \%$ & & $22 \%$ & $13 \%$ \\
Upper limit & $72 \%$ & $47 \%$ & & $65 \%$ & $68 \%$ \\
\hline
\end{tabular}


press) and 87-95\% survival for short-tailed shearwaters Puffinus tenuirostris (Bradley, Wooller, and Skira 1989; Wooller and Bradley 1996).

\subsection{Relationship Between Capture Rate and Effort}

We found no evidence for a relationship between capture rate and effort. This may be because the study area was small, the majority of birds were easy to capture (being in burrows), and the fact that Richdale worked on his own at roughly the same time each year. Apart from the 1953-1954 season, the estimates of capture were fairly consistent, ranging from 43 to $53 \%$ for breeders and from 20 to $39 \%$ for nonbreeders; for 1953-1954, the estimates were $85 \%(\mathrm{SE}=3.2 \%)$ and $83 \%(\mathrm{SE}=5.1 \%)$, respectively. These results suggest that using number of nights as a measure of effort fails to encapsulate all the factors affecting capture rate.

\subsection{Nonbreeders Were Harder to Capture}

Richdale (p. 83) estimated that surface birds had a lower apparent survival rate of $88.2 \%$. He believed that this was because these birds were young nonbreeders and harder to capture, but he had no way of testing this hypothesis. He did test the hypothesis that newly arrived birds had a lower survival rate than established birds by separately estimating the survival of birds banded prior to a particular year ("old" birds) and those banded that year ("new" birds). He found between 1952 and 1953 that $92.9 \%$ of old birds survived while only $83.7 \%$ of new birds did so. The fact that he needed to make an approximate assessment such as this is a good example of the difference between an empirical and a model-based analysis. It was not possible for him to estimate the effect of capture heterogeneity any other way since the theoretical background for mark-recapture had not been developed. Our analysis lends support to his hypotheses, albeit indirectly, as we were not able to separate the three categories of nonbreeder in the analysis.

\subsection{Reproductive Costs}

Life history theory predicts a cost of reproduction on future survival (Fisher 1930; Williams 1966; Reznick 1985). Multistate capture-recapture models have been suggested as a useful method of addressing the possible trade-off between reproduction and survival (see review in Nichols and Kendall (1995) and Clobert (1995) and references therein). There is no evidence from our analysis to indicate a reproductive cost (Table 4), the estimates from the best model suggesting that, if anything, the successful breeders are fitter than other birds (Table 6). A possible explanation for this result is that the breeding pool contains mostly older, experienced birds that are able to cope better with environmental fluctuation than the younger, inexperienced nonbreeders. Our nonbreeder category may contain prebreeders, which are likely to have a lower apparent survival rate due to dispersal associated with prospecting for a suitable location at which to breed for the first time. This implies that the difference in survival between breeders and actual nonbreeders may be smaller than we have estimated here. 


\subsection{Transition Rates}

The mean rate at which nonbreeders became breeders in the following year was consistently more than twice that in the opposite direction (Table 7), which ties in with the apparent population growth during the period 1942-1953 (Table 8; Figure 1). Richdale discussed the encroachment of breeding Stewart Island shags (Phalacrocorax chalconotus) onto the vegetated habitat, which led to the loss of one third of all burrows on Whero Island between 1954 and 1956. The sudden increase in the rate at which breeders became nonbreeders during the period 1953-1956 (Table 7) and the apparent downturn in population size in 1953-1954 appear to tie in with this loss of burrows. These results illustrate well the way in which multistate mark-recapture models can quantify processes that otherwise can only be described.

\section{CONCLUSIONS}

Empirical analysis and our mark-recapture modeling produced similar estimates for survival rates. However, the modeling approach also provided estimates of precision and allowed us to address biologically significant questions not raised by the original researcher. We found some evidence for two biological conclusions that the original researcher suggested but could not prove: nonbreeders have both a lower survival and a lower capture rate than breeders. We believe reanalysis should be carried out more frequently on historical data. However, it appears that currently many biologists do not adequately archive their data for future analysis. Furthermore, in a scientific environment that emphasizes the need for original work, it is becoming rare for such data to be available for future scrutiny.

\section{ACKNOWLEDGMENTS}

We would like to thank the Hocken Library of the University of Otago for permission to use the diaries and manuscripts of Lance Richdale. We thank Richard Barker and two anonymous referees for comments on this paper. But mostly we thank the late Lance Richdale for a life devoted to the seabirds of Southern New Zealand and for the foresight to preserve his notebooks and manuscripts in such perfect order that the working for each table and conclusion in all his many papers can be easily found. If only modern researchers were so meticulous and organized!

[Received August 2000. Accepted October 2000.]

\section{REFERENCES}

Arnason, A. N. (1972), "Parameter Estimates From Mark-Recapture Experiments on Two Populations Subject to Migration and Death," Researches on Population Ecology, 13, 97-113.

(1973), "The Estimation of Population Size, Migration Rates, and Survival in a Stratified Population," Researches on Population Ecology, 15, 1-8.

Bradley, J. S., Wooller, J. D., and Skira, I. J. (1989), “Age-Dependent Survival of Breeding Short-Tailed Shearwaters Puffinus tenuirostris,” Journal of Animal Ecology, 58, 175-188.

Brownie, C., Hines, J. E., Nichols, J. D., Pollock, K. H., and Hestbeck, J. B. (1993), “Capture-Recapture Studies for Multiple State Including Non-Markovian Transitions," Biometrics, 49, 1173-1187. 
Buckland, S. T., Burnham, K. P., and Augustin, N. H. (1997), “Model Selection: An Integral Part of Inference," Biometrics, 53, 603-618.

Burnham, K. P. (in press), “On Random Effects Models for Tag-Recovery and Capture-Recapture Data," in Statistics in Ecology and Statistics in Ecology and Environmental Monitoring III, Dunedin, New Zealand: Otago University Press.

Cam, E., Hines, J. E., Monnat, J.-Y., Nichols, J. D., and Danchin, E. (1998), “Are Adult Non-Breeders Prudent Parents? The Kittiwake Model," Ecology, 79, 2917-2930.

Clobert, J. (1995), “Capture-Recapture and Evolutionary Ecology: A Difficult Wedding," Journal of Applied Statistics, 22, 989-1008.

Cuthbert, R., Fletcher, D., and Davis, L. S. (in press), “A Sensitivity Analysis of Hutton's Shearwater: Prioritizing Conservation, Research and Management," Biological Conservation.

Fisher, R. A. (1930), The Genetical Theory of Natural Selection, Oxford: Clarendon Press.

Hamer, K. C., and Hill, J. K. (1993), "Variation and Regulation of Meal Size and Feeding Frequency," Journal of Animal Ecology, 62, 441-450.

Lack, D. (1968), Ecological Adaptations for Breeding in Birds, Oxford: Oxford University Press.

Lebreton, J.-D., Burnham, K. P., Clobert, J., and Anderson, D. R. (1992), “Modeling Survival and Testing Biological Hypotheses Using Marked Animals: A Unified Approach With Case Studies,' Ecological Monographs, 62, 67-118.

Loery, G., Nichols, J. D., and Hines, J. E. (1997), "Capture-Recapture Analysis of a Wintering Black-Capped Chickadee Population in Connecticut, 1958-1993," Auk, 114, 431-442.

Nichols, J. D., and Kendall, W. L. (1995), “The Use of Multi-State Capture-Recapture Models to Address Questions in Evolutionary Ecology,” Journal of Applied Statistics, 22, 835-846.

Oka, N., Maruyama, N., and Skira, I. (1987), "Chick Growth and Mortality of Short-Tailed Shearwaters in Comparison With Sooty Shearwaters, as a Possible Index of Fluctuations of Australian Krill Abundance," Proceedings of the National Institute of Polar Research Symposium on Polar Biology, 1, 166-174.

Reznick, D. (1985), "Costs of Reproduction: An Evaluation of the Empirical Evidence," Oikos, 44, 257-267.

Richdale, L. E. (1942), "Whero: Island Home of Petrels and Other Birds," Emu, 42, 85-105.

_ (1943), "Whero: Island of Sea-Birds," Wild Life Series, 1, 26-40. Dunedin: Otago Daily Times. (1944), "The Sooty Shearwater in New Zealand," Condor, 46, 93-107. (1945), "The Nestling of the Sooty Shearwater," Condor, 47, 45-62.

(1954), "Duration of Parental Attentiveness in the Sooty Shearwater," Ibis, 96, 586-600.

(1963), "The Biology of the Sooty Shearwater Puffinus griseus," Proceeding of the Zoological Society of London, 31, 1-86.

Ricklefs, R. E., Day, C. H., Huntington, C. E., and Williams, J. B. (1985), "Variability in Feeding Rate and Meal Size of Leach's Storm-Petrel at Kent Island, New Brunswick,” Journal of Animal Ecology, 54, 883-898.

Schwarz, C. J., Schweigert, J. F., and Arnason, A. N. (1993), "Estimating Migration Rates Using Tag-Recovery Data," Biometrics, 49, 177-193.

Teiepa, T., Lyver, P., Horsley, P., Davis, P. J., Bragg, M., Moller, H. (1997), “Co-Management of New Zealand's Conservation Estate by Maori and Pakeha: A Review," Environmental Conservation, 24, 236-250.

Warham, J., and Wilson, G. J. (1982), "The Size of the Sooty Shearwater Population at the Snares Islands, New Zealand," Notornis, 29, 23-30.

Weimerskirch, H. (1998), "How Can a Pelagic Seabird Provision Its Chick When Relying on a Distant Food Resource? Cyclic Attendance at the Colony, Foraging Decision and Body Condition in Sooty Shearwaters," Journal of Animal Ecology, 67, 99-109.

White, G. C., and Burnham, K. P. (1999), "Program MARK: Survival Estimation From Populations of Marked Animals,” Bird Study, 46 (Supplement), 120-138.

Williams, G. C. (1966), "Natural Selection, the Cost of Reproduction, and a Refinement of Lack's Principle," America Naturalist, 100, 687-690.

Wooller, R., and Bradley, S. (1996), "Monogamy in a Long-Lived Seabird: The Short-Tailed Shearwater," in Partnerships in Birds. The Study of Monogamy, ed. J. M. Black, Oxford: Oxford University Press, pp. 223-234. 